NASA Technical Memorandum 106326

\title{
Optimal Synthesis of Hot Composite Laminates With Interphase Layers
}

Christopher Rabzak

Sverdrup Technology Inc.

Lewis Research Center Group

Brook Park, Ohio

Dimitris A. Saravanos

Ohio Aerospace Institute

NASA Lewis Research Center

Cleveland, Ohio

and

Christos C. Chamis

National Aeronautics and Space Administration

Lewis Research Center

Cleveland, Ohio

Prepared for the

Symposium on Functionally Graded, Advanced Composite Materials sponsored by SES, ASME, and ASCE

Charlottesville, Virginia, June 6-9, 1993 


\title{
OPTIMAL SYNTHESIS OF HOT COMPOSITE LAMINATES WITH INTERPHASE LAYERS
}

\author{
Christopher Rabzak \\ Sverdrup Technology, Inc. \\ Lewis Research Center Group \\ Brook Park, Ohio 44142 \\ Dimitris A. Saravanos \\ Ohio Aerospace Institute \\ Lewis Research Center Group \\ Cleveland, Ohio 44135 \\ and \\ Christos C. Chamis \\ National Aeronautics and Space Administration \\ Lewis Research Center \\ Cleveland, Ohio 44135
}

\section{SUMMARY}

A method for the optimal grading of a single interphase layer in metal matrix composite laminates for the minimization of residual stresses is described. The capability to simultaneously tailor some fabrication parameters is also incorporated. Applications for unidirectional, cross-ply and quasi-isotropic Graphite/Copper laminates are investigated to assess the potential of interphase layer in reducing matrix residual stresses in various laminate configurations. Simultaneous optimization of interphase and fabrication characteristics appears to be more effective in decreasing residual stresses. The results also indicate that the interphase layer is more effective in lowering residual stresses in unidirectional composites and selectively within individual plies of a laminate. Embedded interphase layers in all the plies did not produce a significant global reduction in residual stresses.

\section{INTRODUCTION}

Advanced composite laminates are potential materials for use in a wide variety of structural applications, from aircraft engines to electronic equipment. They exceed conventional monolithic alloys and superalloys in maintaining superior properties in high temperature environments and offer lower density which results

\footnotetext{
*NASA Resident Research Associate at Lewis Research Center.
} 
in weight savings. In addition, unlike conventional materials, the micromechanical and macromechanical characteristics of the composites may be tailored for specific requirements. Representative methods for the optimal design of traditional composite structures are reported in the literature ${ }^{1,2,3,4,5}$.

However, a limiting factor in the thermomechanical performance of hot laminates, that is laminates incorporating matrices capable to sustain elevated temperatures and undergo inelastic deformations, is the development of either intraply residual microstresses resulting from the differing thermomechanical material properties between the constituents, or ply and interlaminar macrostresses resulting from different properties and fiber orientations between the various plies. These stresses develop during the composite fabrication process as a laminate cools from a high processing temperature to ambient conditions. Residual stresses have been found to reach critical levels, and in many cases, matrix microcracking has been observed in postfabricated specimens. ${ }^{6}$

Various efforts to reduce or control residual stresses have been mostly concentrated in unidirectional composites, and we selectively mention the tailoring of the fabrication process ${ }^{7}$ and the introduction of interphase layer(s) with tailored thermomechanical characteristics $8,9,10,11$. These previous studies have independently predicted the ability of an interphase to reduce residual microstresses in unidirectional composites. However, it appears that the validity of the approach in multi-layered laminates has not been investigated yet. Unidirectional configurations have limited practical applicability, as opposed to multidirectional laminates, which are used in most applications involving multiple thermomechanical loads. Therefore the extension of previous work to enable the grading (also referred hereafter as interphase grading) of interphases in many plies of a laminate is required in order to identify interfacial characteristics for maximum reductions in residual stresses with minimum sacrifice in laminate properties. 
Consequently, the current paper presents a formal methodology for either predicting the optimal thermomechanical characteristics of a interphase layer in order to minimize matrix residual stresses in multiple plies of composite laminates, or the fabrication process, or both. An incremental non-linear composite mechanics approach is used to calculate the thermomechanical inelastic response of the laminate. The residual stresses in the constituents include contributions from the dissimilar properties at both the intraply and laminate levels. Residual stresses are minimized either uniformly through-thethickness (all plies) or selectively (at targeted plies). The optimization problem is numerically solved with non-linear programming techniques. Evaluation of the method using a high modulus Graphite(P100)/Copper composite system are presented and the effectiveness of interphase layers is investigated in three laminate configurations, $[0]_{8},\left[0_{2} / 90_{2}\right]_{s}$, and $[0 / \pm 45 / 90]_{s}$.

\section{COMPOSITE MECHANICS}

The composite behavior during fabrication is computationally simulated with a nonlinear composite mechanics approach developed by Chamis and co-workers ${ }^{12,13,14}$ at NASA Lewis Research Center and encoded into a computer program METCAN (METal matrix Composite ANalyzer). The micromechanics utilize, among other factors, three material phases (fiber, matrix, and interphase), the effects of temperature, the inelastic response of the constituent materials, and the build-up of residual microstresses to obtain ply level results. Laminate mechanics based on classical laminate theory are then utilized to obtain the macroscopic results. The basic elements of the composite mechanics pertinent to this study are summarized herein.

The micromechanics incorporate a unit-cell model packed in a square array. An idealization of a single unit cell is shown in Figure 1. Three material phases exist within the model: the fiber ( $f$ ), the matrix (m), and the interphase (d). Consequently, three distinct micro-regions are recognized in the composite material which are identified with superscripts $A$ (composed of matrix), $B$ (composed of matrix-interphase), and $C$ (composed of matrix-interphase-fibers). Micro-regions $A, B$ and $C$ have different average properties, 
therefore, mechanical or thermal loads result in the development of different average stresses. A square fiber cross-section is assumed to enhance accuracy in the prediction of transverse properties and stresses. The micromechanics involve closed-form expressions to predict equivalent homogeneous properties for the unit cell or ply equivalent thermal and mechanical properties, ply in-plane uniaxial strengths, and thermomechanical constituent stresses. Further details of the micromechanics equations are summarized elsewhere $^{14}$.

The most notable assumption in this micromechanical model involves the discretization of the ply in the three microregions A, B, and C (Figure 1). Since the formulation of the composite micromechanics is based on the principles of displacement compatibility and force equilibrium, the micromechanics will be accurate in an average sense. The present method is consistently formulated on the average stresses and properties in these microregions, hence, the results and trends will be also accurate within the average context of the micromechanical formulation.

The nonlinear effects of state variables, such as temperature $(T)$ and stress $(\sigma)$, on the in situ properties $(P)$ of the constituent materials are approximated by the following form:

$$
\frac{P_{j}^{t}}{P_{o j}}=\left[\frac{\left(T_{M j}-T^{t}\right)}{\left(T_{M j}-T_{o}\right)}\right]^{q}\left[\frac{\left(S_{j}^{t}-\sigma_{j}^{t}\right)}{S_{j}^{t}}\right]^{p} j=m, d, f
$$

where: subscript $j$ indicates matrix, interphase, or fibers; subscript $o$ reference conditions; subscript $M$ the melting point. Candidate properties for this equation are the moduli $(E)$, Poisson's ratios $(\nu)$, ultimate strengths $(S)$, and $\operatorname{CTE}(\alpha)$. Reference properties usually denote the value of the respective property at ambient temperature condition. The first term in the right hand side of Equation 1 represents the temperature effects on the property, and the second term the inelastic effects of high stresses on the property. Superscript $t$ represents time at any load step. However, time effects, such as creep and stress relaxation, 
have been neglected. Each term on the right hand side of Equation 1 represents a monotonic functional dependence of $P_{j}^{t} / P_{o j}$ from some reference property value to a terminal or ultimate material state.

The specific shape of the function depends on the exponents $(q$ and $p)$ in Equation 1 which are calibrated from correlations with experimental data. Because of the material non-linearity expressed by Equation 1, the calculation of composite properties and microstresses at each time step of the simulated fabrication phase requires an iterative solution of the governing equations.

The thermomechanical response at the laminate level is predicted using the classical Kirchoff-Love kinematic assumptions. Integration of the ply stress-strain equations through-the-thickness of the laminate yields the thermomechanical laminate relations,

$$
\begin{aligned}
& \{N]=[A]\left\{e^{o}\right\}+[C]\{k\}-\left\{N_{T}\right\} \\
& \{M\}=[C]\left\{e^{o}\right\}+[D]\{k\}-\left\{M_{T}\right\}
\end{aligned}
$$

where: $\{N\}=\left(N_{x}, N_{y}, N_{x y}\right)$ and $\{M\}=\left(M_{x}, M_{y}, M_{x y}\right)$ are the in-plane force and moment vectors applied on the laminate; $\left\{\epsilon^{\circ}\right\}$ and $\{k\}$ are the mid-plane extensional strain and curvature respectively. $\left\{N_{T}\right\}$ and $\left\{M_{T}\right\}$ represent the generalized thermal stresses (forces and moments) due to through-the-thickness variations in ply stiffness, ply anisotropy, coefficients of thermal expansion $\left\{\alpha_{c}\right\}$, and possible temperature gradients, as follows:

$$
\left(\left\{N_{T}\right\},\left\{M_{T}\right\}\right)=\sum_{i=1}^{N_{t}}\left[Q_{c}\right]_{i}\left\{\alpha_{c}\right\}_{i} \Delta T_{i}\left(\left(h_{t}-h_{b}\right)_{i}\left(h_{t}^{2}-h_{b}^{2}\right)_{i} / 2\right)
$$

where $N_{1}$ is the number of plies. $[A],[C],[D]$ are the extensional, coupling and flexural stiffness matrices of the laminate respectively. Additionally, $\left[Q_{c}\right]$ is the off-axis ply stiffness matrix, and $h_{t}, h_{b}$ are distances from the top and bottom of the ply. 


$$
\left.([A],[C],[D])=\sum_{i=1}^{N_{l}}\left[Q_{d}\right]_{i}\left(h_{t}-h_{b}\right),\left(h_{t}^{2}-h_{b}^{2}\right)_{i} / 2,\left(h_{i}^{3}-h_{b}^{3}\right)_{i} \beta\right)
$$

An incremental procedure is used to simulate the nonlinear composite response. In this context, the mechanical laminate loads, temperature, and the resultant stresses at time $t+\Delta t$ are the sum of the respective quantities at time $t$ and their increments during time step $\Delta t$, that is:

$$
\begin{gathered}
\left\{N^{t+\Delta t}\right\}=\left\{N^{t}\right\}+\left[N^{\Delta t}\right\}, \quad\left\{M^{t+\Delta t}\right\}=\left\{M^{t}\right\}+\left\{M^{\Delta t}\right\} \\
T^{i+\Delta t}=T^{t}+T^{\Delta t} \\
\left\{\sigma_{j}^{i+\Delta t}\right\}=\left\{\sigma_{j}^{t}\right\}+\left\{\sigma_{j}^{\Delta t}\right\}
\end{gathered}
$$

where the quantities with time superscripts and without time superscripts indicate cumulative and incremental quantities respectively. The subscript $j$ indicates either a ply or a material microregion. The incremental stresses in Equation 8 induced by the incremental mechanical loads $\{N\},\{M\}$, and temperature $T$, are calculated based on the previously outlined mechanics.

\section{OPTIMAL SYNTHESIS}

The proposed method aims to optimally control the development of residual microstresses by optimization of the fabrication process and interphase characteristics. Considering the large number of parameters, design criteria and the complexity of the simulation, this may be best accomplished with non-linear mathematical programming (NLP). A standard constrained NLP problem involves the minimization of an objective function:

$$
\min F(z)
$$

subject to side and performance constraints of the following form: 


$$
\begin{gathered}
z^{L} \leq z \leq z^{U} \\
Q_{j}(z) \leq 0 \quad j=1, \ldots, J
\end{gathered}
$$

The design variables are represented by the vector $z$; superscripts $U$ and $L$ indicate upper and lower bounds; and $Q(z)$ are the inequality performance constraints. Equations 10 and 11 define the feasible domain for the optimization variables. In the present paper the design vector includes: temperatures and consolidation pressures of the fabrication process; thermomechanical and geometrical characteristics (thickness) of the interphase.

The minimization of the matrix residual stresses, either in all the plies or in specified plies, is proposed as the objective function. The reduction of residual stresses in the matrix is a highly desirable objective in hot composites. Although, minimum matrix stresses do not necessarily represent an optimum stress state, this objective function is merely used to demonstrate the method. Other objective functions relating to the durability of the composite laminate are presently being investigated.

Considering that radial and transverse to the longitudinal axis cracks (see Figure 2) are more commonly observed in hot composite laminates, the axial and transverse circumferential stresses are included in the objective function. Among the many possible ways for these stresses to be minimized simultaneously, the minimization of the maximum stress is proposed for its tendency to always achieve more uniform reductions,

$$
\min \left(\max \left(\sigma_{m_{11}}^{k}, \sigma_{m_{22}}^{k}\right\}\right) \quad k=1, \ldots, N_{l}
$$

where superscript $k$ indicates the $\mathrm{k}$-th ply.

Based on previous work in unidirectional composites, it is anticipated that high residual stresses will develop in the graded interphases ${ }^{7,8,9}$. Additional development of mechanical stresses may occur since consolidation pressures are tailored, and it is possible that thermomechanical stresses during fabrication may exceed the 
corresponding strength limits of all constituents. To safe-guard against this possibility of failure, constraints are imposed on the matrix $(m)$, interphase $(d)$, and fiber $(f)$ microstresses of all plies at various time steps $t$ during the fabrication process in the form of the maximum stress criterion,

$$
\begin{gathered}
S_{m i j}^{C}<\sigma_{m i j}^{t}<S_{m i j}^{T} \\
S_{d i j}^{C}<\sigma_{d i j}^{t}<S_{d i j}^{T} \\
S_{f i j}^{C}<\sigma_{f i j}^{t}<S_{f j}^{T}
\end{gathered}
$$

The superscripts $C$ and $T$ identify compressive and tensile strengths respectively, and subscripts $i, j$ indicate the applicable stress component. $S$ is the ultimate material strength at the corresponding thermomechanical state. An additional constraint is imposed on the interphase thickness $h_{d}$, to ensure that the interphase does not exceed the boundaries of the unit cell. In the case of square packing of fibers the constraint may proved to be:

$$
1+2 \frac{h_{d}}{d_{f}}-\sqrt{\frac{\pi}{4} k_{f}} \leq 0
$$

where $d_{f}$ is the fiber diameter and $k_{f}$ is the fiber volume ratio.

To ensure that the critical properties of the fabricated laminate will remain within acceptable limits, lower bounds $(L)$ are imposed on the diagonal extensional and flexural stiffness of the laminate. The lower bounds are defined by the user. 


$$
\begin{aligned}
& A_{11} \geq A_{11}^{L} \\
& A_{22} \geq A_{22}^{L} \\
& D_{11} \geq D_{11}^{L} \\
& D_{22} \geq D_{22}^{L}
\end{aligned}
$$

\section{Optimization Technique}

The micromechanics code (METCAN) and the optimization methods were incorporated in to a computer code MMLT (Metal Matrix Laminate Tailoring). The method of feasible directions was used to solve the previously defined optimization problem due to its ability to confine the search within the feasible domain ${ }^{15}$. The computational implementation for the solution of the optimization problem is schematically shown in Figure 3. The modified feasible directions algorithm performs a direct search within the feasible optimization domain. The search direction is estimated from first order sensitivity of the objective function and the active constraints. A line search follows along the calculated search direction. The implemented algorithm includes an active set strategy, that is only the constraints near violation are included in the search, thus allowing the efficient handling of the large number of constraints involved.

\section{APPLICATION CASES}

\section{Materials and Assumptions}

A composite material consisting of high modulus graphite fiber (P100) and copper matrix was chosen since there is a wide availability of property data (Table 1 ). Ply thicknesses were assumed 0.01 inch, thus laminate thicknesses were maintained constant.

Unless otherwise stated, the optimized interphase characteristics included the modulus $\left(\mathrm{E}_{\mathrm{d}}\right)$, coefficient of thermal expansion $\left(\alpha_{d}\right)$, ultimate tensile strength $\left(S_{d}\right)$, and thickness $\left(h_{d}\right)$. The interphase thickness is defined 
as a fraction of the total fiber diameter. Bounds on the interphase characteristics, shown in Table 2, were used in all cases. Concurrent tailoring of the fabrication process with the interphase properties was also performed as described in the following paragraphs. The initial interphase properties for optimization were taken as the matrix for all cases. The initial and final temperatures and pressures which define four linear segments of temperature and pressure profiles were used as design variables. The initial fabrication process was assumed to consist of a linear temperature drop subject to a low constant consolidation pressure.

The laminate configurations considered are: (1) a unidirectional configuration $\left[\mathrm{O}_{8}\right] ;(2)$ a cross-ply $\left[0_{2} / 90_{2}\right]_{s}$ laminate; and (3) a quasi-isotropic $[0 / \pm 45 / 90]_{\mathrm{s}}$ laminate. A 0.4 fiber volume ratio (FVR) was considered in all cases, with the exception of the $90^{\circ}$ plies in the $[0 / \pm 45 / 90]_{s}$ laminate. Earlier configuration selection revealed that the residual stresses in the $90^{\circ}$ plies of the quasi-isotropic laminate were exceeding their failure limits during fabrication, and a FVR of 0.45 was assumed to alleviate this problem. All laminate configurations involve minimization of the maximum matrix residual stress with the addition of a interphase layer in all plies. Selective interphase embedment and minimization of residual stresses in one of the plies of the quasi-isotropic laminate was also investigated.

\section{Unidirectional Composite}

\section{Optimization of Interphase Properties Only}

The resulting residual stresses with the addition of an optimum interphase in the $[0]_{8}$ composite are shown in Figure 4. The percentages denote the change in residual stresses from their initial value. The matrix and fiber longitudinal residual stresses were reduced. The transverse residual stress in the matrix has been virtually eliminated. This was accomplished by an interphase whose predicted properties, shown in Table 3 , were reduced by $25 \%$ compared to the properties of the matrix. The interphase thickness increased to the imposed upper bound. Since the secant modulus of the interphase is related to the ultimate strength 
(Equation 1) the decrease in strength indicates a trend for a ductile interphase which will reach a compliant state (yielding) before the matrix, rather than a trend for a weak interphase. This, in conjunction with the stress constraint (Equation 14), indicates that as the residual stresses increase in the predicted optimal interphase it acts as a compliant layer during the processing phase. The formation of such compliant layer is apparently reducing the thermal stresses in both fiber and matrix. The optimal coefficient of thermal expansion (CTE) of the interphase was lower than the matrix CTE but greater than that of the fiber. This intermediate CTE decreases the gradient of thermal expansion mismatch.

\section{Simultaneous Optimization of Interphase and Fabrication}

The advantages of concurrent optimization in reducing the residual stresses can clearly be seen in Figure 5. Significant additional decreases occurred in the matrix longitudinal residual stress while the transverse stress was again virtually eliminated.

As in the previous case, the predicted increase of consolidation pressure at the end of processing phase (see Figure 6) combined with the lower strength and modulus of the interphase causes the interphase to yield before the matrix during the fabrication. The predicted high consolidation pressure facilitates further the formation of a compliant interphase layer during fabrication, this is why additional reductions in the residual stresses were observed. It is also stressed, that in the present case the interphase does not act as a compliant layer after the consolidation pressure is removed. The assumed inelastic response was critical in achieving the formation of this "processing induced" compliant layer, instead of a compensating layer which may result when elastic constituents are assumed ${ }^{9}$. The optimal CTE of the interphase was again scaled between the fiber and matrix, but closer to the matrix since there were changes in the processing profiles, as shown in Figure 6. 


\section{Crose-ply Laminate}

Because of the observed beneficial interaction between interphase tailoring and fabrication tailoring, in the remaining cases the interphase is concurrently optimized with processing variables. The optimization of the modulus, strength, and CTE of the interphase layer in all plies of the $\left[0_{2} / 90_{2}\right]_{8}$ laminate resulted in. particularly strong reductions in the transverse matrix stress as shown in Figure 7 . For this case, the interphase thickness was not included in the design variables. The residual stress reductions in the matrix were less than in the case of the unidirectional composite, indeed, only the transverse stresses were decreased by approximately $50 \%$. The stress reductions were again achieved by an increase in the optimal consolidation pressure and an optimal interphase of nearly 50\% lower strength, as seen in Figure 8 and Table 4 respectively. The pressure increase was not as great as in the unidirectional case. The optimum interphase modulus and CTE did not reduce as much as in the unidirectional case.

Overall, the introduction of tailored interphase layers in the cross-ply laminate does not appear as effective as in the case of the unidirectional composite. Intralaminar residual macrostresses appear to be the controlling factor. Part of the residual stresses is induced in the laminate level by the radically different thermomechanical properties occurring between the $0^{\circ}$ and $90^{\circ}$ plies. Hence it seems that the interphase layer reduced mostly the portion of the residual stresses generated in the intraply (micromechanics) level. This trend is further reinforced in the following case.

\section{Quasi-isotropic Laminate}

\section{Global Interphase Optimization}

The effectiveness of global interphase grading in conjunction with a more complex quasi-isotropic laminate configuration $[0 / \pm 45 / 90]_{\mathrm{s}}$ is discussed here. This is an excellent example, because in contrast to the previous 
cases the laminate exhibits a pseudo-isotropy in the extensional stiffness matrix [A]. Yet, the laminate incorporates significantly higher interlaminar inhomogeneity as a result of additional plies and fiber orientation angles. As seen in Figure 9, the addition of tailored interphases in all plies produced only a modest uniform reduction in the longitudinal matrix stresses of all plies. It seems that the increased intralaminar thermal macrostresses and competing factors at the ply and laminate levels reduce further the effectiveness of global interphase grading. The optimal interphase properties are slightly (less than $10 \%$ difference) greater than the matrix (see Table 5), which also depicts the ineffectiveness of the global interphase optimization.

\section{Selective Interphase Optimization}

The addition of an interphase in the $90^{\circ}$ ply to minimize only the residual stresses in these plies was also considered. As seen in Figure 10, significant transverse matrix stress reductions occurred in the $90^{\circ}$ plies while the remaining stresses displayed little change. The resultant optimal interphase strength (see Table 5) was reduced substantially (similarly to the unidirectional case) indicating once again the trend of an interphase which yields prematurely than the matrix during fabrication. The optimal interphase modulus is slightly greater than the modulus of the matrix, and the CTE is close to the matrix value. Apparently, the selective inclusion of an interphase layer in the $90^{\circ}$ plies reduced the local microstresses without as many competing effects from the interphases in other plies. The present case demonstrated that the inclusion of tailored interphase layers in selective plies may effectively reduce the residual stresses locally, and validated the possibility to engineer graded composites with tailored interphases in select plies.

\section{CONCLUSIONS}

A methodology was presented for the optimal synthesis of hot composite laminates with a embedded graded interphase layer between fiber and matrix. Critical characteristics of the interphase layers were optimized 
for minimal matrix residual stresses in the various plies of the laminate. Additional constraints were imposed on the thermomechanical stresses of the interphase, matrix, and fibers during the fabrication to ensure the integrity of the material. The capability to simultaneously tailor processing parameters was also incorporated. The inelastic thermomechanical response of the composite laminate was simulated with incrementally nonlinear composite mechanics. The resultant optimization problem was solved numerically with non-linear programming.

Evaluations were presented on unidirectional, cross-ply, and quasi-isotropic Graphite/Copper laminates. Simultaneous optimization of interphase and fabrication characteristics appears to be more effective in reducing the residual stresses. The trends in resultant optimal interphases and processes indicate a tendency for a ductile interphase layer that yields before the matrix. Thus, a compliant layer between the fibers and matrix is formed during fabrication in connection with high consolidation pressure. These different results were attributed to the assumed inelastic behavior.

The interphase layer was found more effective in reducing locally or selectively residual microstresses induced by intraply constituent in-homogeneities, either in unidirectional composites or with selectively embedded tailored interphase layers in some plies. However, embedded interphase layers in all plies were found to be less effective in reducing globally the residual stresses in multi-directional laminate. In view of these results, addition work on the effectiveness of the interphase layer in other laminate configurations is required.

\section{REFERENCES}

1. Schmit, L. A., and Farhsi, B. (1977). Optimum Design of Laminated Fibre Composite Plates. International Journal for Numerical Methods in Engineering, Vol. 11, 4, pp. 623-640. 
2. Vanderplaats, G. N., and Weisshaar, T. A. (1989). Optimum Design of Composite Structures. International Journal for Numerical Methods in Engineering, Vol. 27, 4, pp. 437-448.

3. Hajela, P., and Shih, C. J. (1989). Optimal Design of Laminated Composites Using a Modified Mixed Integer and Discrete Programming Algorithm. Computers and Structures, Vol. 32, 1, pp. 213-221.

4. Brown, K. W. (1988). Structural Tailoring of Advanced Turboprops (STAT) - Intern Report. NASA CR-180861.

5. Saravanos, D. A., and Chamis, C. C. (1992) Multiobjective Shape and Material Optimization of Composite Structures Including Damping. ALAA Journal, Vol 30, 3, pp. 805-813.

6. Brown, Alan S. (1993). High-Temperature Materials Warm Up for Debut. Aerospace America - March, p. 20.

7. Saravanos, D. A., Chamis, C. C., and Morel, M. (1991). Concurrent Tailoring of Fabrication Process and Interphase Layer to Reduce Residual Stresses In Metal Matrix Composites. SAMPE Quarterly Vol. $6,4,36-44$.

8. Arnold, S. M. (1990). Elastic/Plastic Analyses of Advanced Composites Investigating the Use of Compliant Layer Concept in Reducing Residual Stresses Resulting from Processing. NASA TM 103204.

9. Jansson, S., and Leckie, F. A. (1990). Reduction of Thermal Stresses in Continuous Fiber Reinforced Metal Matrix Composites With Interface Layers. NASA CR-185302

10. Morel, M. R., Saravanos, D. A., and Chamis, C. C. (In Press). Tailoring of Inelastic Metal-Matrix Laminates with Simultaneous Processing Considerations. Journal of Composites Science and Technology.

11. Pindera, M. J., and Freed, A. D., and Arnold, S. M. (1992). Effects of Fiber Interfacial Layer Architectures on the Thermoplastic Response of Metal Matrix Composites. NASA TM 105802

12. Chamis, C. C., Murthy, P. L. N., and Hopkins, D. A. (1988). Simulation of High Temperature Metal Matrix Composites Cyclic Behavior. NASA TM-102115. 
13. Murthy, P. L. N., Hopkins, D. A., and Chamis, C. C. (1989). Metal Matrix Composite Micromechanics: In-Situ Behavior Influence on Composite Properties. NASA TM-102302.

14. Hopkins, D. A., and Chamis, C. C. (1985). A Unique Set of Micromechanics Equations for High Temperature Metal Matrix Composites. NASA TM-87154

15. Vanderplaats, G. N. (1984). Numerical Optimization Techniques for Engineering Design: With Applications. McGraw-Hill Book Company, New York. 
Table 1. Constitutive Material Properties (reference conditions)

\begin{tabular}{|l|l|l|l|l||}
\hline \hline Property & $\begin{array}{l}\text { Fiber } \\
\text { (Graphite) }\end{array}$ & $\begin{array}{l}\text { Temperature } \\
\text { Exponents }\end{array}$ & $\begin{array}{l}\text { Matrix } \\
(\mathrm{Cu})\end{array}$ & $\begin{array}{l}\text { Temperature } \\
\text { Exponents }\end{array}$ \\
\hline $\mathrm{E}_{11}\left(\times 10^{6} \mathrm{psi}\right)$ & 105.0 & .25 & 17.7 & .3 \\
\hline $\mathrm{E}_{22}\left(\times 10^{6} \mathrm{psi}\right)$ & 0.9 & .25 & 17.7 & .3 \\
\hline$\nu_{12}(\mathrm{in} / \mathrm{in})$ & 0.2 & .25 & 0.3 & 0.0 \\
\hline $\mathrm{G}_{12}\left(\times 10^{6} \mathrm{psi}\right)$ & 1.1 & .25 & 6.8 & - \\
\hline$\nu_{23}(\mathrm{in} / \mathrm{in})$ & 0.25 & .25 & 0.3 & 0.0 \\
\hline$\alpha_{11}(\mathrm{ppm})$ & -0.9 & .25 & 9.8 & .21 \\
\hline$\alpha_{22}(\mathrm{ppm})$ & 0.560 & .25 & 9.8 & .21 \\
\hline $\mathrm{S}_{11}\left(\times 10^{3} \mathrm{psi}\right)$ & 325.0 & .25 & 32.0 & 2.85 \\
\hline $\mathrm{S}_{22}\left(\mathrm{x} 10^{3} \mathrm{psi}\right)$ & 200.0 & .25 & 32.0 & 2.85 \\
\hline $\mathrm{S}_{12}\left(\mathrm{x} 10^{3} \mathrm{psi}\right)$ & 195.0 & .25 & 19.2 & \\
\hline $\mathrm{T}_{\mathrm{m}}\left({ }^{\circ} \mathrm{F}\right)$ & 6000.0 & & 1980.0 & - \\
\hline
\end{tabular}

Table 2. Bounds imposed on interphase variables

\begin{tabular}{||l|c|c|}
\hline \multicolumn{1}{|c|}{ Property } & Lower Limit & Upper Limit \\
\hline Modulus $\mathrm{E}_{\mathrm{d}},\left(\mathrm{x} 10^{6} \mathrm{psi}\right)$ & 5.0 & 80.0 \\
\hline CTE $\alpha_{\mathrm{d}},(\mathrm{ppm})$ & 0.005 & 98.0 \\
\hline Strength $\mathrm{S}_{\mathrm{d}},(\mathrm{ksi})$ & 5.0 & 50.0 \\
\hline Thickness $\left(\mathrm{h}_{\mathrm{d}} / \mathrm{d}_{\mathrm{f}}\right),(\%)$ & 5 & 15 \\
\hline
\end{tabular}


Table 3. Optimal interphase properties; $[0]_{8}$ composite

\begin{tabular}{|l|c|c|c|}
\hline \multicolumn{1}{|c|}{ Property } & $\begin{array}{c}\text { Initial } \\
\text { (matrix) }\end{array}$ & $\begin{array}{c}\text { Optimal } \\
\text { Interphase }\end{array}$ & $\begin{array}{c}\text { Optimal } \\
\text { Interphase \& } \\
\text { Fabrication }\end{array}$ \\
\hline $\begin{array}{l}\text { Modulus, } \mathrm{E}_{\mathrm{d}} \\
\left(\mathrm{x} 10^{6} \mathrm{psi}\right)\end{array}$ & 17.7 & $13.3(-25 \%)$ & $12.5(-30 \%)$ \\
\hline $\begin{array}{l}\mathrm{CTE}, \alpha_{\mathrm{d}} \\
(\mathrm{ppm})\end{array}$ & 9.8 & $5.9(-40 \%)$ & $6.8(-30 \%)$ \\
\hline $\begin{array}{l}\text { Strength, } \mathrm{S}_{\mathrm{d}} \\
(\mathrm{ksi})\end{array}$ & 32.0 & $23.5(-27 \%)$ & $29.0(-10 \%)$ \\
\hline Thickness, $\left(\mathrm{h}_{\mathrm{d}} / \mathrm{d}_{\mathrm{f}}\right),(\%)$ & 12.0 & $15.0(+20 \%)$ & $15.0(+20 \%)$ \\
\hline
\end{tabular}

Table 4. Optimal interphase properties; $\left[\mathrm{O}_{2} / \mathrm{SO}_{2}\right]_{8}$ laminate

\begin{tabular}{||l|c|c|}
\hline \multicolumn{1}{|c|}{ Property } & $\begin{array}{c}\text { Initial } \\
\text { (matrix) }\end{array}$ & $\begin{array}{c}\text { Optimal } \\
\text { Interphase \& } \\
\text { Fabrication }\end{array}$ \\
\hline $\begin{array}{l}\text { Modulus, } \mathrm{E}_{\mathrm{d}} \\
\left(\mathrm{x} 10^{6} \mathrm{psi}\right)\end{array}$ & 17.7 & $18(0 \%)$ \\
\hline $\begin{array}{l}\mathrm{CTE}, \alpha_{\mathrm{d}} \\
(\mathrm{ppm})\end{array}$ & 9.8 & $9.0(-10 \%)$ \\
\hline $\begin{array}{l}\text { Strength, } \mathrm{S}_{\mathrm{d}} \\
(\mathrm{ksi})\end{array}$ & 32.0 & $17.2(-54 \%)$ \\
\hline $\begin{array}{l}\text { Thickness, }\left(\mathrm{h}_{\mathrm{d}} / \mathrm{d}_{\mathrm{f}}\right) \\
(\%)\end{array}$ & 12.0 & 12.0 (Constant) \\
\hline
\end{tabular}

Table 5. Optimal interphase properties; $[0 / \pm 45 / 90]_{\mathrm{g}}$ laminate configuration

\begin{tabular}{|l|c|c|l||}
\hline \multicolumn{1}{|c|}{ Property } & $\begin{array}{c}\text { Initial } \\
\text { (matrix) }\end{array}$ & $\begin{array}{c}\text { Global } \\
\text { Interphase } \\
\text { Optimization }\end{array}$ & $\begin{array}{c}\text { Optimal } \\
\text { Selective } \\
\text { Optimization }\end{array}$ \\
\hline $\begin{array}{l}\text { Modulus, } \mathrm{E}_{\mathrm{d}} \\
\left(\mathrm{x} 10^{6} \mathrm{psi}\right)\end{array}$ & 17.7 & $19(+7 \%)$ & $18.7(+6 \%)$ \\
\hline $\begin{array}{l}\mathrm{CTE}, \alpha_{\mathrm{d}} \\
(\mathrm{ppm})\end{array}$ & 9.8 & $10.6(+8 \%)$ & $9.2(-7 \%)$ \\
\hline $\begin{array}{l}\text { Strength, } \mathrm{S}_{\mathrm{d}} \\
(\mathrm{kpsi})\end{array}$ & 32.0 & $32.8(+2 \%)$ & $8.6(-30 \%)$ \\
\hline $\begin{array}{l}\text { Thickness, }\left(\mathrm{h}_{\mathrm{d}} / \mathrm{d}_{\mathrm{f}}\right) \\
(\%)\end{array}$ & 12.0 & $14.0(+15 \%)$ & $12.8(7 \%)$ \\
\hline
\end{tabular}




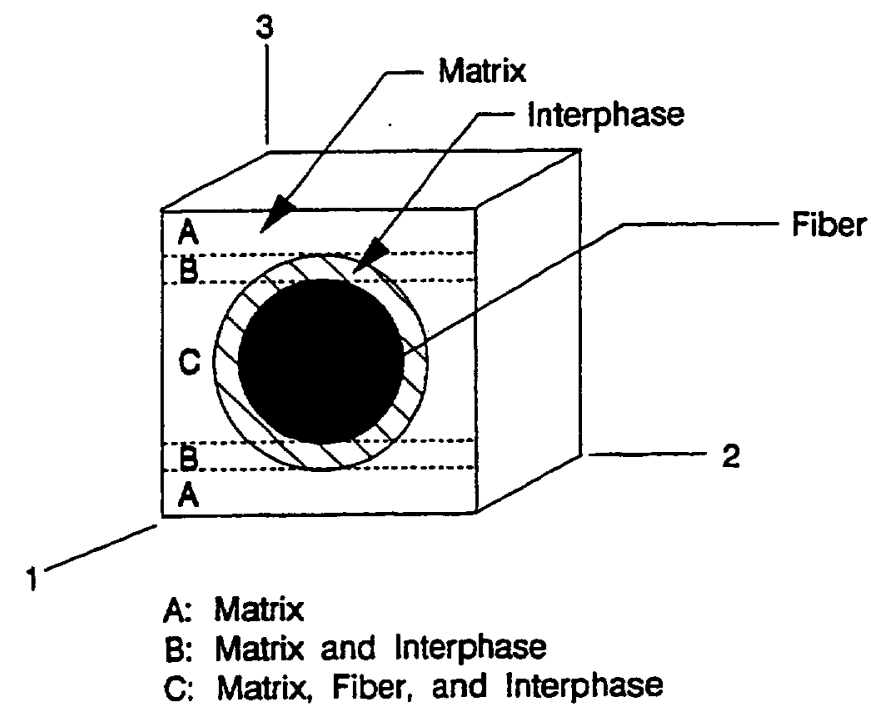

Figure 1.-Unit cell for composite micromechanics in METCAN.

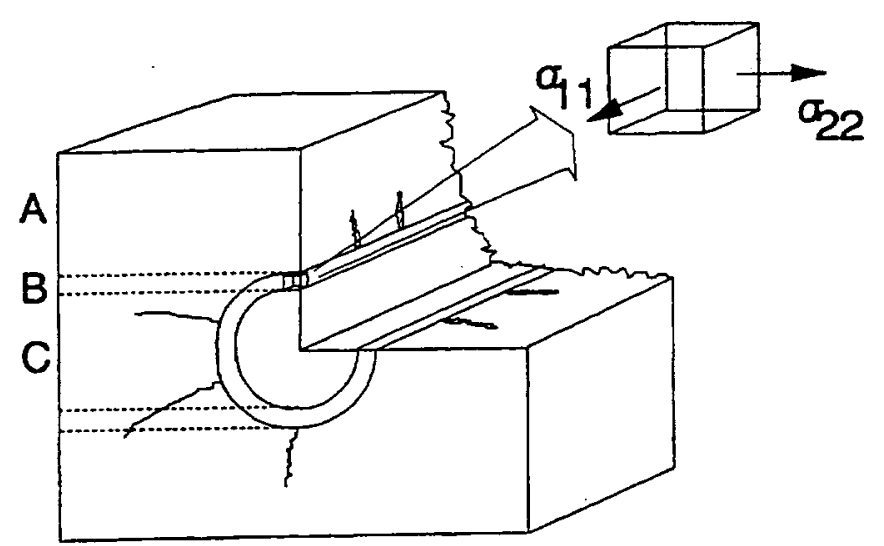

Figure 2-Effect of residual stresses on matrix microcracking.

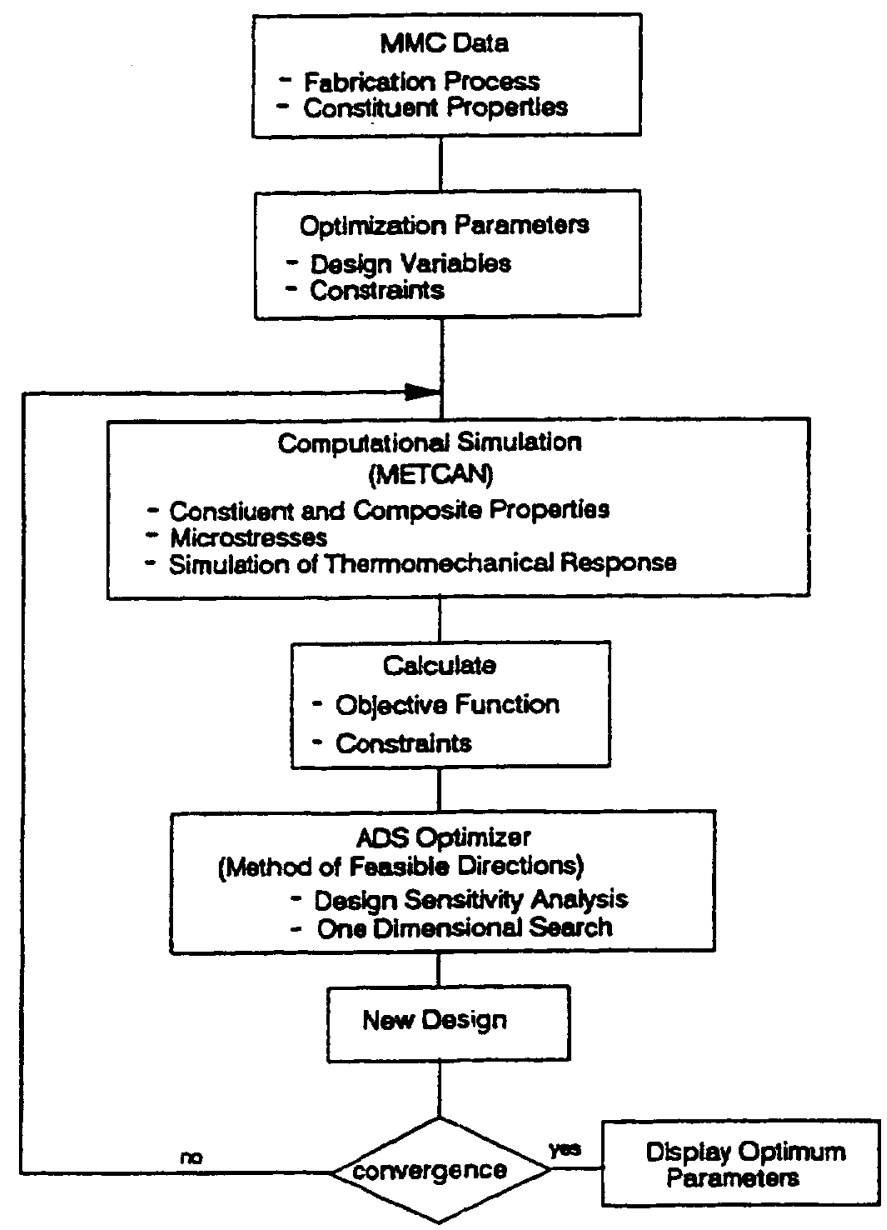

Figure 3.-MMLT computational procedure to concurrently optimize the fabrication process and interphase.

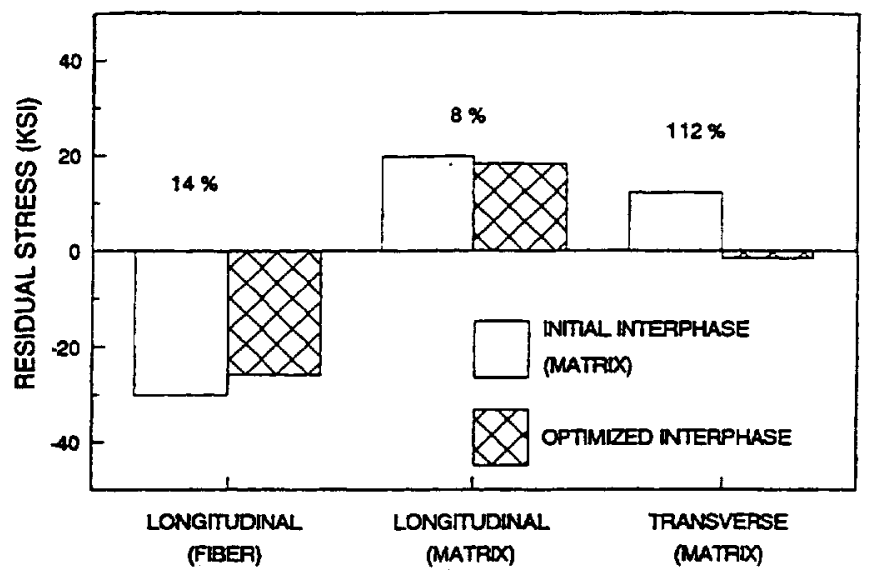

Figure 4.-Reduction of residual stresses in $[0]_{8}$ composite with graded interphase. 


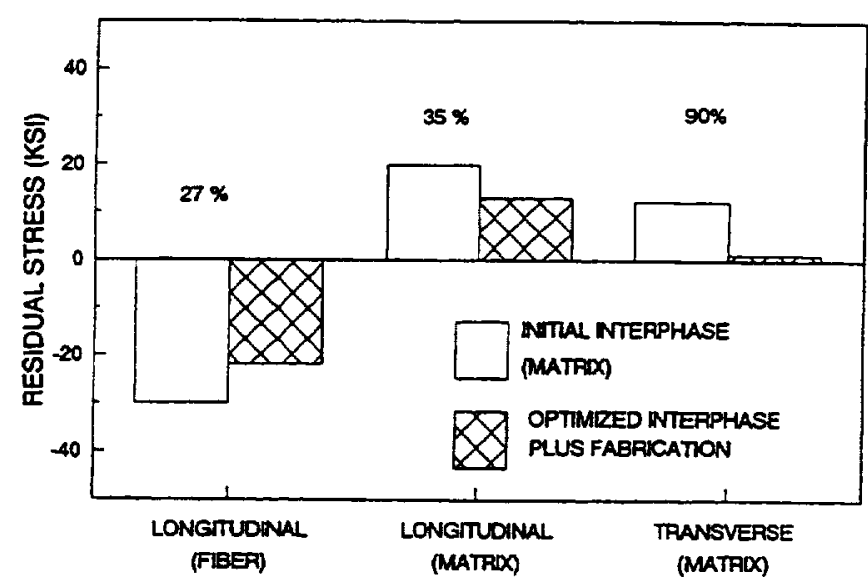

Figure 5.-Reduction of residual stresses in $[0]_{8}$ composite with concurrent interphase grading and fabrication tailoring.
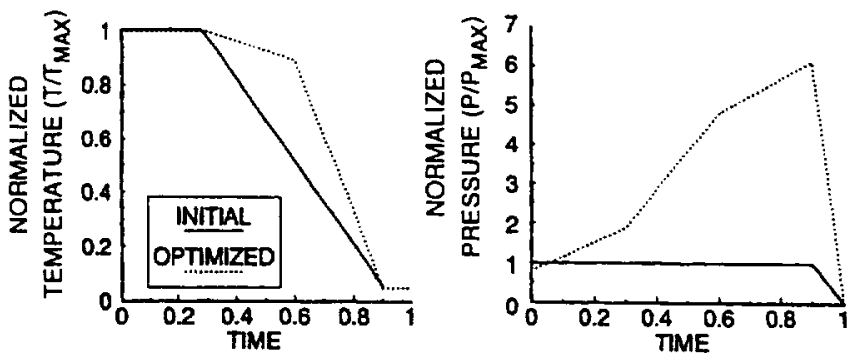

Figure 6.-Initial and tailored fabrication process for $[0]_{8}$ composite.

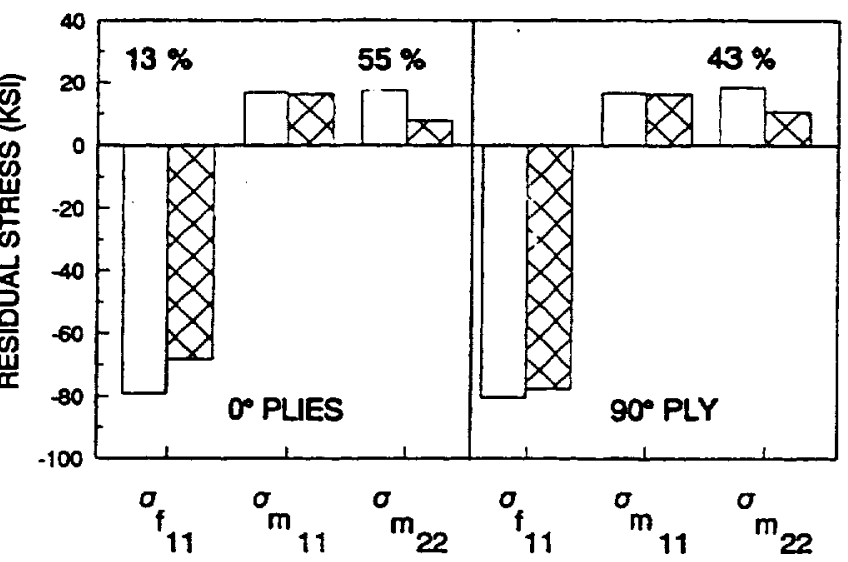

Figure 7.-Reduction of residual stresses in $\left[\mathrm{O}_{2} / 9 \mathrm{O}_{2}\right]_{3}$ laminate with global (all plies) interphase grading and concurrently tailored fabrication.
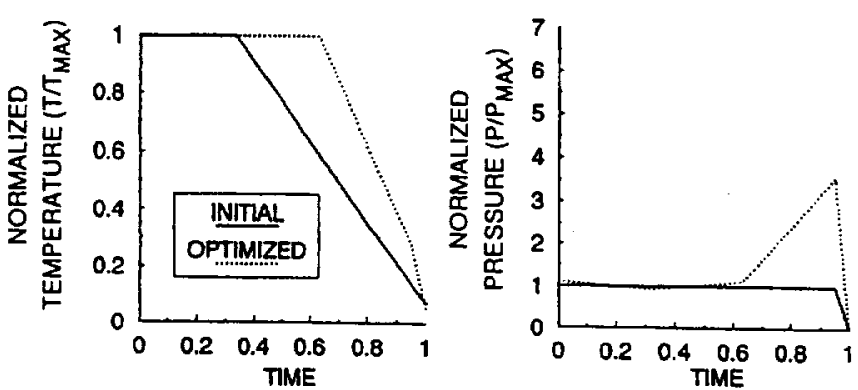

Figure 8.- Optimum fabrication process for $\left[0_{2} / 90_{2}\right]_{s}$ laminate.

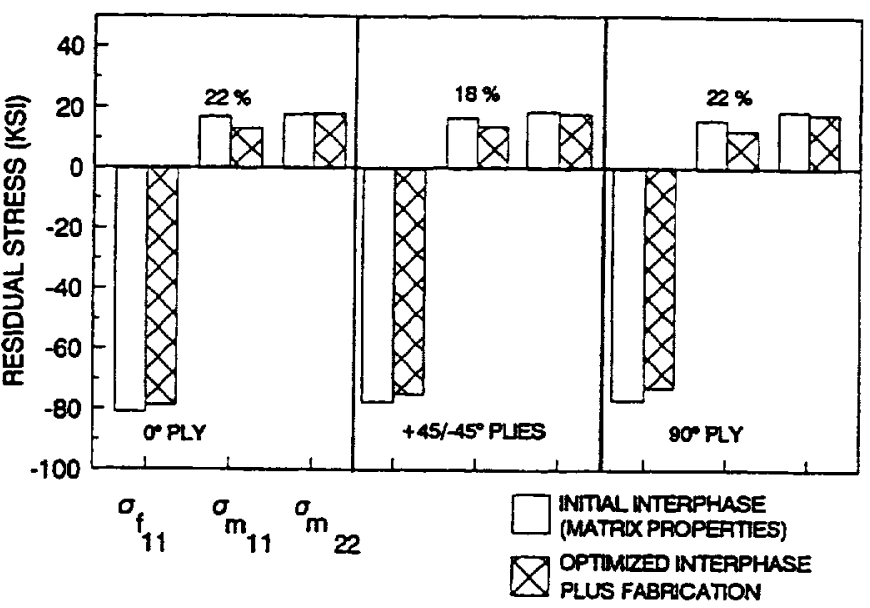

Figure 9.-Reduction of residual stresses in $[0 /+45 / 90]$, laminate with global (all plies) interphase grading and concurrently tailored fabrication.

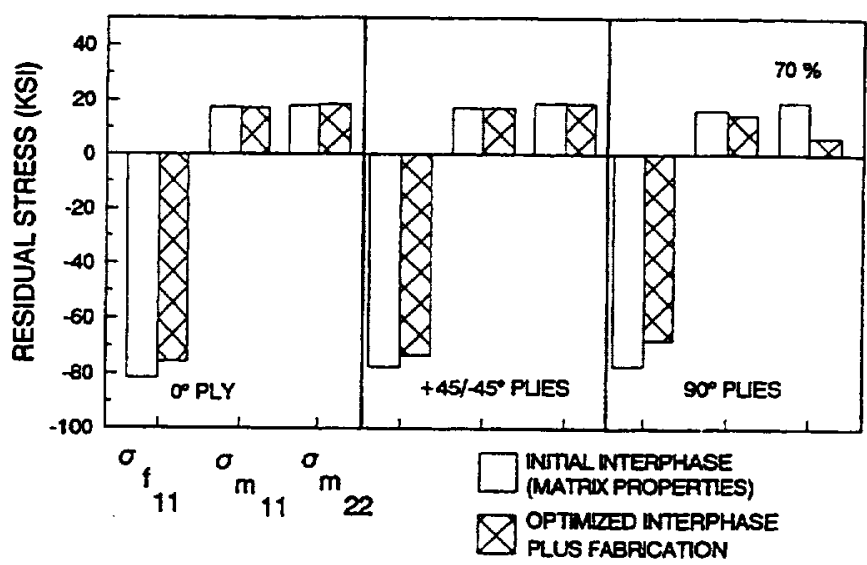

Figure 10.-Reduction of stresses with selective interphase grading $\left(90^{\circ}\right.$ plies only) and concurrent fabrication tailoring; $[0 /+45 / 90]_{s}$ laminate. 

Public reporting burden for this collection of information is estimated to average I hour per response, including the time for reviewing instructions, searching existing data sources, gathering and maintaining the data needed, and completing and reviewing the collection of information. Send comments regarding this burden estimate or any other aspect of this

collection of information, including suggestions for reducing this burden, to Washington Headquarters Services, Directorate for Information Operations and Reports, 1215 Jefler
Davis Highway. Suite 1204, Artington, VA 22202-4302, and to the Office of Management and Budget. Papenwork Reduction Project (0704-0188), Washington, DC 20503.

\begin{tabular}{l|l|l} 
1. AGENCY USE ONLY (Leave blank) & 2. REPORT DATE & 3. REPOAT TYPE AND DATES COVERED
\end{tabular}

\begin{tabular}{|l|l|l|l|}
\hline & June 1993 & Technical Memorandum \\
\hline
\end{tabular}

4. TIRE AND SUBTITLE

5. FUNDING NUMBERS

Optimal Synthesis of Hot Composite Laminates With Interphase Layers

6. AUTHOR(S)

WU-510-01-50

Christopher Rabzak, Dimitris A. Saravanos and Christos C. Chamis

7. PERFORMING ORGAMIZATION NAME(S) AND ADDRESS(ES)

8. PERFoRming ORGANIZATION

REPORT NUMBER

National Aeronautics and Space Administration

Lewis Research Center

E-8081

Cleveland, Ohio 44135-3191

9. SPONSORING/MONITORING AGENCY NAME(S) AND ADDRESS(ES)

10. SPONSORING/MONTORING AGENCY REPORT NUMBER

National Aeronautics and Space Administration

Washington, D.C. 20546-0001

NASA TM-106326

11. SUPPLEMENTARY NOTES

Prepared for the Symposium on Functionally Graded, Advanced Composite Materials sponsored by SES, ASME and ASCE, Charlottesville, Virginia, June 6-9, 1993. Christopher Rabzak, Sverdrup Technology Inc. Lewis Research Center Group, 2001 Aerospace Parkway, Brook Park, Ohio 44142; Dimitris A. Saravanos, Ohio Aerospace Institute, 22800 Cedar Point Road, Brook Park, Ohio 44142 and Christos C. Chamis, NASA Lewis Research Center, Cleveland. Ohio. Responsible person, Chrisios C. Chamis, (216) 433-3252.

12a. DISTRIBUTION/AVAILABILTTY STATEMENT

12b. DISTRIBUTION CODE

Unclassified - Unlimited

Subject Category 24

13. ABSTAACT (Maximum 200 words)

A method for the optimal grading of a single interphase layer in metal matrix composite laminates for the minimization of residual stresses is described. The capability to simultaneously tailor some fabrication parameters is also incorporated. Applications for unidirectional, cross-ply and quasi-isotropic Graphite/Copper laminates are investigated to assess the potential of interphase layer in reducing matrix residual stresses in various laminate configurations. Simultaneous optimization of interphase and fabrication characteristics appears to be more effective in decreasing residual stresses. The results also indicate that the interphase layer is more effective in lowering residual stresses in unidirectional composites and selectively within individual plies of a laminate. Embedded interphase layers in all the plies did not produce a significant global reduction in residual stresses.

\section{SUBJECT TERMS}

Composite materials; Laminates; Interphase; Coatings; Optimization; Residual stresses; Fabrication; Graphite; Copper

17. SECURITY CLASSIFICATION
OF REPORT
Unclassified

\begin{tabular}{|c|c|}
\hline $\begin{array}{c}\text { 18. SECURITY CLASSIFICATION } \\
\text { OF THIS PAGE } \\
\text { Unclassified }\end{array}$ & $\begin{array}{c}\text { 19. SECURTY CLASSIFICATION } \\
\text { OF ABSTRACT } \\
\text { Unclassified }\end{array}$ \\
\hline
\end{tabular}

